Opportunities for redistributed manufacturing and digital intelligence as enablers of a circular economy

Mariale Moreno $^{\mathrm{a}}$, Matt Wright ${ }^{\mathrm{a}}$, Richard Court ${ }^{\mathrm{b}}$ and Fiona Charnley ${ }^{*}$

${ }^{a}$ Centre for Competitive Creative Design, Cranfield University, Cranfield,

Bedfordshire, UK; ${ }^{b}$ Newcastle University, Newcastle, UK.

* Centre for Competitive Creative Design, College Road, Cranfield University, Cranfield, Bedfordshire, MK43 0AL, UK f.j.charnley@cranfield.ac.uk 


\section{Opportunities for redistributed manufacturing and digital intelligence as enablers of a circular economy}

The linear production of consumer goods is characterized by mass manufacture by multinational enterprises and globally dispersed supply chains. The current centralised model has created a distance between the manufacturer and end user, limiting the opportunity for intelligent circular approaches for production and consumption. Through a mixed method approach opportunities of circularity are explored for the consumer goods sector. The study presents four lenses to analyze three enterprises through a multi-case study approach to explore the potential of digital intelligence and redistributed manufacturing (RDM) as enablers of circular business models. In addition, the study examines whether Discrete Event Simulation can be used to evaluate the circular scenarios identified through quantifying flows of material that determine traditional economic value (cost/tonne). The mixed method approach demonstrates that, a qualitative systemic analysis can reveal opportunities for circularity, gained through implementing 'digital intelligence' and distributed models of production and consumption. Furthermore, simulations can provide a quantified evaluation on the effects of introducing circular activities across a supply chain.

Keywords: Circular Economy; redistributed manufacturing (RDM); digital intelligence; discrete event simulation.

\section{Introduction}

We live in a linear economy of take-make-dispose in which, a growing middle class of 1 billion new consumers by 2020 (Kharas 2010) is increasing not just our consumption patterns but also the levels of waste generated. It is estimated that 1.3 billion tons of municipal solid waste are generated globally every year (Hoornweg \& Bhada-Tata 2012). In addition, resource use globally is growing at higher rates possessing a major threat to the planetary boundaries in which human economic activities could operate (Schaffartzik et al., 2014). These planetary boundaries are starting to be recognized by many companies as they acknowledge that the linear system increases their exposure to risk, as the environmental costs associated with the depletion of natural capital 
increases, resulting in price volatility and higher resource prices (Ellen MacArthur Foundation, 2012).

The concept of a Circular Economy has emerged as a policy goal in the context of decoupling economic growth from increasing resource use, as well as promoting waste reduction (Gregson et al., 2015). The concept has gained significant attention across both Industry and Academia. Scholars (Bakker et al., 2014; Bocken et al., 2014, Lewandoski 2016; Gregson et al., 2015) recognise that the circular economy as a concept has a long standing history located in the fields of sustainability, environmental and development studies, and has emerged from multiple schools of thought including Industrial Ecology (Frosh and Gallopolus 1989), Industrial Symbiosis (Ayres and Simonis 1995, Chertow 2007), the Performance Economy (Stahel 1981, 2010, 2013) Natural Capitalism, (Hawken, et al., 2013), Biomimicry (Benyus, 2002), and Cradle to Cradle (McDonough and Braungart 2002). Organisations such as the Ellen MacArthur Foundation (EMF) working in partnership with McKinsey, have more recently popularized the concept within industry through a series of reports (i.e. Ellen MacArthur 2012, 2013, 2014), explaining the potential of the circular economy to specific sectors such as the consumer goods industry (Ellen MacArthur Foundation 2013). As a result, three fundamental principles have been proposed to aid the transition towards a circular economy (Ellen MacArthur Foundation 2012):

- Principle 1 - Preserve and enhance natural capital by controlling finite stocks and balancing renewable resource flows: Keep stock of materials and resources available for a better-performance.

- Principe 2 - Optimize resource yields by circulating products, components, and materials at the highest utility at all times in both technical and biological cycles: by designing for remanufacturing, refurbishing and recycling to keep technical 
components and materials circulating in the economy, preserving embedded energy and other value. It also refers to encouraging biological nutrients to reenter the biosphere in the safest way as possible to become valuable feedstock for a new cycle.

- Principle 3 - Foster system effectiveness by revealing and designing out negative externalities: this includes managing externalities, such as land use, air, water and noise pollution, the release of toxic substances, and climate change; to reduce damages to food security, mobility, shelter, education, health, and entertainment.

Globalization trends in the consumer goods sector have influenced the industrial landscape with individual international manufacturing production sites serving regional and global markets (Srai et al., 2016). As such, the consumer goods industry has changed very little in the last 30 years, and its growth has been predominantly based on building capacity and markets on a global scale within every part of the value chain (Chatterjee et al., 2010). However, current trends such as decentralization of one or more activities of the value chain so the final product is manufactured closer to the final user (Srai et al., 2016); the increasing demand for personalised products (Delloite, 2015), the use of emerging technologies in the design and manufacture of consumer goods (Manyika et al., 2015); and the increasing demand for open innovation platforms in which co-creation through shared knowledge occurs between the consumer, designer and producer (Srai et al., 2016) demand new levels of value and innovation for this industry (Rauch et al., 2016). Changes are already occurring within specific industrial sectors (e.g. pharmaceutical), in which emerging technologies enable micro-factories and smaller manufacturing processes that are closer to the end user, referred to as (re-) distributed manufacturing (Rauch et al., 2016, Srai et al., 2016). This study aims to 
examine the potential for and possible criticisms of 're-distributed manufacturing' and 'digital intelligence' to act as enablers of a circular economy in the context of the consumer goods industry.

\section{Background}

To understand how '(re-)distributed manufacturing' and 'digital intelligence' could act as enablers of a circular economy, it is necessary to consider how these terms are intertwined. The literature refers primarily to distributed manufacturing and has been acknowledged in research and practice as a way to move from current centralised manufacture to decentralised 'glocal' production to meet local needs with a global perspective (Rauch et al., 2016). In addition, distributed manufacturing is characterized by technological developments in engineering and computing, bringing new capabilities in terms of automation, complexity, flexibility and efficiency (Srai et al., 2016). The use of technological developments (e.g. information communication technologies, automation and robotics, big data analytics, additive manufacturing, cloud computing and mobile technologies) that could enable intelligent and digitally networked manufacturing systems, is what is referred in this paper as 'digital intelligence.'

Freeman, McMahon and Godfrey (2017) described redistributed manufacturing (RDM) as a smaller-scale local manufacturing process, often using new production technologies, such as computer-enabled additive layer manufacturing. According to them, these technologies are reshaping and redefining markets and supply chains as they enable small-scale production of artefacts that in the past would have required a large capital investment in production plant. RDM is also defined as 'the shift from centralised to decentralised manufacture with the aim to create a more resilient and connected system taking advantage of digital intelligence and newly emerging technologies, to provide an agile, user driven approach that will allow localised 
production of goods to meet global demands' (Moreno \& Charnley, 2016). As seen, current research on RDM integrates digital intelligence at its core to move towards a more localised model of production and consumption.

Current advocates of RDM (Matt et al., 2015, Kohtala 2015, Rauch et al., 2015, Zanetti et al., 2015; DeVor et al., 2012), have considered how small-scale, flexible manufacturing networks could bring environmental benefits leading to more sustainable forms of production and consumption. These compliment the circular economy principles, as redistributed production could reduce emissions due to less transportation, could help to manage better resource use through implementing energy-efficiency and resource saving manufacturing systems (Malik et al., 2011; Srai et al., 2015); and could result in improved use of resources and materials through enabling recovery and recycling (Manyika, 2012). In contrast, Fox and Alptekin (2018) argue that the sustainability of different manufacturing distributions would depend on economic, ecological, social and institutional factors; and would not always offer environmental benefits. For example, digitally enabled RDM models could benefit from the reduction of ecological impact through reducing long distance transport, but at the same time could increase emissions caused by the formulation, transmission and storage of digital manufacturing data $(\mathrm{Xu}, 2012)$.

The current literature on distributed manufacture focuses on examining the potential advantages and disadvantages to environmental sustainability (see: Fox and Alptekin, 2018 for an extended version of these studies), but neglects to examine how principles of circularity could be applied. In addition, as one of the goals of a circular economy is to decouple growth from resource use, there is a need to quantify its benefits and draw-backs on economic value to further understand the potential of RDM as an enabler of circular manufacturing systems. To close this knowledge gap and 
achieve the proposed aim, the research is structured as follows: 1) A review of current literature was conducted, looking at previous schools of thought that apply circular economy principles (e.g. industrial ecology, performance economy, cradle-to-cradle, natural capitalism, closed-loop supply chain, and closed production and operation systems) as well as current research in the area; 2) The literature was linked to the concepts of digital intelligence and RDM, identifying references to the benefits and constraints of localised models of production and consumption as well as the use of digital technologies; 3) This resulted in identifying four lenses (system enablers, supporting systems, product design, and business model) to consider when looking at the potentials of RDM and digital intelligence as enablers of a circular economy and 4) Through a qualitative analysis of three different case studies of the consumer goods sector, this potential was examined. Furthermore, to provide a quantified evaluation on the effects of introducing circular activities into the supply chain of these case studies, Discrete Event Simulation (DES) was used to quantify flows of material that determine an economic value (cost/tonne) to the circularity potential of these intelligent and redistributed models of consumption and production.

\section{Systematic Review of Literature}

The review looked at past and present schools of thought that had an influence on the concept of a circular economy and its principles. Whilst conducting the literature review, an analytical framework of four lenses, inspired by the four building blocks ${ }^{1}$ of circular economy, was developed to categorise the literature according to current business aspects and their potential to be transformed through the application of the

\footnotetext{
${ }^{1}$ Developed by the Ellen MacArthur Foundation, the four building blocks to a transition to a circular economy are: Circular Economy Design, New Business Models, Reverse Cycles, Enablers of system conditions (see: https://www.ellenmacarthurfoundation.org/circulareconomy/building-blocks)
} 
three circular economy principles. The literature review focused on business aspects beyond institutional aspects, as the starting point of this study was that businesses acknowledge that a linear system cannot be sustained, and therefore they are accountable for sustainable practices.

As mentioned, each lens corresponds to a business aspect: Lens 1 - Supporting Systems refers to the different stakeholders and operations within a supply chain; Lens 2 System Enablers considers factors alongside the application of technology in manufacturing systems, that facilitate and support the required systemic change; Lens 3 - Design refers to the design and innovation of products and services; and Lens 4 refers to the Business Model. While analysing the literature, the emergence of these four lenses became apparent, and thus the following framing questions were used when classifying the literature according to these lenses to examine the potential of RDM and digital intelligence as enablers of a circular economy.

- Supporting Systems: The current consumer goods sector relies on complex and international supply chains. However, a circular economic model will require to redesign the current supply chain as a supportive system, to recover consumer goods material through reuse, remanufacture and decomposition (Ellen MacArthur Foundation, 2013). The introduction of digital intelligence to manufacturing systems is enabling a transformation within supply chains (Rüßmann et al., 2015). Smart production processes are enabling faster, flexible and efficient manufacturing systems shortening supply chains (Rauch et al., 2016). Therefore, developing an understanding of the transformation of current supply chains as a supportive system, was necessary. As such, this lens aims to explore how the supply chain would have to be transformed to support a circular 
system through questions such as: are their opportunities for a redistributed manufacturing model? What would be the associated challenges and benefits?

- System enablers: The shift to a circular economy model will require a number of enablers to facilitate and support the required systemic change. One way to enable systemic change is through the generation of digital intelligence to gain a better understanding of our current systems, (i.e. current infrastructure, policy and technological systems, amongst others) and identify opportunities for innovation (Ellen MacArthur Foundation 2016a). As such, it was necessary to understand what the current digital intelligence capabilities of businesses today are. This lens aims to explore future opportunities in which data and digital solutions can be used to drive innovation by asking: what impact will the introduction or advancement of digital intelligence capabilities have on design, business models, and supply chain?

- Design: The use of digital intelligence in localised manufacturing systems is driving radical changes in how products and serviced are designed (Sari et al., 2016; Rauch et al., 2016). Design also plays a key role in the transition towards a circular economy (Bocken et al., 2016; Bakker et al., 2014; Braungart and McDonough, 2002). As such, this lens looks at the role of design within this context to develop an understanding of the current products/services. This lens aims to explore how the product or service could be re-designed to facilitate a closed-loop system by asking; are there opportunities to improve the design of products by selecting the right material and follow circular design practices such as using modular components, design for disassembly, design for reuse and remanufacture, design for longevity and emotional attachment? 
- Business Model: Lacy and Rutqvist (2015) argue that circular economy has the potential to fundamentally change the ways in which businesses operate and allows for the development business models that move beyond incremental efficiency gains to radical systemic transformations that involve consumer-centric approaches to creating, delivering, and capturing value. This lens aims to explore opportunities for business model innovation by asking; can a RDM business case be created as means to innovate whilst at the same time implement circular economy principles?

\section{Findings from the Systematic Review of Literature}

\section{Supporting Systems}

Supporting systems, refers to the supply chain network of a business. A supply chain network has been defined by Nagurney and Nagurney (2010) as the infrastructure for the production, storage and distribution of products. Manufacturing processes and their supply chains, especially for the consumer goods sector are increasingly globalized (Nagurney et al., 2007). As such, responsibilities towards a more sustainable supply chain does not lay in isolation to a single organisation but are dependent on the performance of its suppliers, transporters and users all over the world (Rahimifard and Clegg, 2007). The second principle of a circular economy and early schools of thought such as Industrial Ecology and Closed-Loop Supply Chains (CLSC) offer opportunities to transform 'waste streams' into valuable material or 'assets' (Wells and Sietz, 2005). This is because, CLSC with a reverse logistics system in place, could allow recovered products to re-enter the supply chain in different forms and types of value. Value is recognized as keeping the physical properties of a product at their highest value through re-use, repair, maintenance or re-manufacture, avoiding the use of virgin resources and 
emissions generated by the production of new goods (Wells and Sietz 2005; Chertow, 2007, Gutowski et al., 2011). Cascading or recycling is also recognized as a viable option to minimize resource use, despite the properties of a product being 'down cycled' for a lower grade of application (Wells and Sietz 2005).

Despite scholars (Guide and Wassenhove 2009, Wells and Sietz 2005) highlighting the economic and environmental potentials of CLSC, in practice there are a number of challenges from a business perspective. CLSC are constantly affected by increased logistic costs such fuel, energy, transport, and labour costs (Itasse 2008). However, RDM models could help to reduce these costs by having a shorter supply chain as well as a reduction on inventory and warehouse costs through localisation and on demand production. (Rauch et al., 2016). Other challenges include the complexity of managing and controlling all actors involved in a CLSC, the lack of market for remanufactured products, the uncertainty of quality of used products, the security of supply of used products, and in many cases operating a CLSC is conditional to contextual factors and product type (Atasu et al., 2013; Wells and Sietz 2005; Guide and Wassenhove 2009). To overcome some of these issues such as quality and security of supply, Schatten (2011) recognise the role of digital intelligence to monitor and control CLSC, identify products and material factions, and even track product status during use. This is further discussed below.

\section{System Enablers}

This lens refers to enabling systemic change through the use of digital intelligence to gain a better understanding of current systems and identify opportunities for innovation (Ellen MacArthur Foundation 2016a). Schatten (2011) and, Ford and Despeisse (2016) have analysed the circularity and sustainability advantages of using digital intelligence in manufacturing systems. These advantages include material savings due to more 
precise production, energy efficient processes for manufacturing, supply chain integration through digital connectivity, and reduced inventory waste due to production on demand. Emerging technology such as 3D printing is allowing smaller scale on demand production (Srai et al., 2016). 3D printing technologies integrated with embedded RFID tags and sensors can enable cloud manufacturing in which product data will be sold instead of the physical product (Helo et al., 2014; Matt et al., 2015) which, combined with process analytics, could enhance production control as well as CLSC (Srai et al., 2016; Parry et al., 2016). However, the circular advantages and the transition towards more localised models of production through the use of digital intelligence are dependent on the technology readiness as well as transformational changes in adopting such technologies (Sari et al., 2016). From an organisational perspective, infrastructural capability, investment in skills and technology development, and privacy and security of shared data amongst the whole supply chain are still underlying questions (Rauch et al., 2016; Sari et al., 2016). As such, a regulatory framework is also necessary as a system enabler, to facilitate the continued development of such technologies towards socio-economic acceptance. For example, it is important to put in place regulations that enable better control of data and shared information through open-source platforms, as currently there are no clear regulations on these aspects (Bresserie et al., 2018).

\section{Design}

In RDM models aided by digital intelligence, the design of new products and services does not only happen within a company, but within a collaborative process between the company and the customer (Kohtala 2015; Rauch et al., 2016). RDM models are characterized by a system in which the production becomes part of the consumption process called 'prosumption' (Kohtala 2015). 'Prosumers' can contribute to the design 
process, allowing a greater customisation and personalisation of products and services. 'Prosumption' also enables design practitioners and manufactures to be closer to the end user allowing the delivery of personalized solutions to their needs (Srai et al., 2016). In addition, design plays an important role to encourage more responsible use of materials and energy, as well as promoting product longevity and closed material loops (Kohtala 2015). These resound with Bakker's (2014) argument on the contribution of design for product life extension for a circular economy. It is acknowledged that some of these customisation benefits would depend on the type of product being manufactured. For example, furniture shops such as Unto-this-Last (see below case study) reduce emissions by producing products on demand and by shipping their final products in compact bulks in a close proximity to their clients (Faludi et al., 2017; Ford and Despeisse, 2016). However, when talking of other complex consumer products made of different materials such as metals and plastics, current technologies used to produce personalised products, such as additive manufacturing, at the moment can produce parts and not whole products. Thus, parts still need to be assembled in centralised facilities, increasing negative externalities associated with transport and energy consumption (Faludi et al., 2017). In addition, the materials used for additive manufacturing are not necessary greener affecting current recycling rates (Ford and Despeisse, 2016).

Furthermore, to assist the transition towards a circular and re-distributed model of production and consumption, design has to move towards an open innovation platform (Rauch et al., 2016). However, this raises questions regarding the robustness and quality of the product, its integrity, and intellectual property implications regarding ownership and copy right infringement (Srai et al., 2016). 


\section{Business Model}

To make a transition towards circular and re-distributed models of production and consumption aided by digital technologies, it is recognized that fundamental changes in the business model will be needed (Bocken et al., 2016; Bakker et al., 2014; Srai et al., 2016; Lacy and Rutqvist 2015). Lewandoski (2016) provides a review of circular business models and Matt et al., (2016) provide a classification for RDM models. In each case, business opportunities are acknowledged. However, in today's current practice, changes in business models have challenges due to cost structures delivering the same quality, control and the necessary infrastructure; as well as challenges related to liability (Fox and Alptekin, 2018).

\section{Methodological Approach}

The research was based on a mixed method approach including: a qualitative analysis of three case studies based in the UK (Splosh, Graze, and Unto this Last) and a quantitative analysis using Discrete Event Simulation (DES), ofcircular opportunities for each of these case studies. The case studies were selected as they use aspects of digital intelligence to operate and represent a decentralised model of production and consumption. A description of each company is provided below.

A. Splosh: is a UK manufacturer that produces concentrated sachets of cleaning products. They provide the user with re-useable bottles in which to insert the sachet along with water. They cut out the retailer as orders are made online and the postal service is used to deliver the products. Splosh has recently changed their product which no longer require adding water. However, this case study was conducted previous this change.

B. Graze: Is an online retailer and manufacturer providing snacks that are personalized and delivered in boxes directly to the end user. They have developed a range of over 
100 snacks and designed an intelligent algorithm (DARWIN - Decision Algorithm Rating What Ingredients Next), to customize each portion and optimize the freshness of ingredients. DARWIN also records the customer's history and preferences, monitors stock levels and tracks the location of workers on the factory floor. They work with small suppliers in Britain and world-wide to provide ingredients and use recyclable materials in their packaging.

C. Unto this Last: is an 'open workshop' based in North London, which enables micromanufacturing at the point of sale. They produce be-spoke furniture to clients' requirements. The manufacturing process uses digitally controlled cutting tools and technologies such as parametric modelling and lean manufacturing, and they have developed software for a flexible production system.

\section{Case Study Analysis}

The objectives of the case study analysis were to:

1. Identify suitable conditions where digital intelligence and RDM act as enablers of circular business models for the consumer goods sector and,

2. Identify opportunities to adopt digital intelligence and a re-distributed model of production and consumption that would enable circular business models within the consumer goods sector.

The research followed a cross-case analysis of secondary data based on independent sources such as news articles and blogs; as well as companies' sources such as reports available online and their websites (Sources are available at: 10.17862/cranfield.rd.c.3392994). All data sourced was selected and thematically analysed separately for each case study using the lenses identified in the literature review (Appendix A). A further, cross-case comparison was conducted through data triangulation (Yin, 2013). The objective of this data triangulation was to identify 
common characteristics amongst the three case studies that could be linked to previous RDM and Circular Economy criteria or themes ${ }^{2}$ identified by Moreno and Charnley (2016), and that could be related to each lens. The cross triangulation followed a thematic coding approach, which is used in a qualitative enquiry as a constructionist method to understand intertwined events operating within society (Robson, 2002). This method allowed the identification of common RDM characteristics for the three case studies, as well as common suitable conditions where digital intelligence could act as an enabler of circular economy activities within the business model.

\section{Modelling / simulation techniques - Discrete Event Simulation (DES)}

A key requirement for understanding the effects of introducing circular economy activities to the case studies investigated in this paper is to be able to quantify both the amounts of material involved and the timeframes within which these materials move. Once amounts of material are known, then further analysis becomes possible on the economic, energy and environmental consequences of change. Several possible methods and research topics could be applied including, Materials Flow Analysis (MFA), research on CLSC, Systems Dynamics (SD), "agent" based modelling and Discrete Event Simulation.

The DES method has been extensively used to model and simulate manufacturing and business processes (Carrie, 1988; Pidd, 1998; Page and Wohlgemuth, 2007), and has encompassed approaches that are event-based, activitybased or process-based. However, the simulations focused on individual businesses or sites, and not on the flow of material over a whole supply chain, as in the case studies

\footnotetext{
${ }^{2}$ Localisation, distributed knowledge, distributed structure, customisation, distributed ownership, value optimisation, resource efficiency, economic viability.
} 
presented here. More importantly, DES has not been used to simulate circular processes (e.g. reuse, remanufacture, and recycle).

A DES specifically tracks "entities" (e.g. components, products, people) within a dynamic, time evolving model of the system under study. Hence DES can be used as a way of uncovering the complex interactions between the existing flows of units of material (i.e. the entities) along the supply chain from supplier, through the business (manufacturer) and on to the end-user, and the new reverse supply and material flows that could be introduced to enable circular material management.

For the DES models created, the key assumptions were to represent the components of each product as the "entities" of the DES. These entities could then be tracked on their progress through the model over time. The numbers of entities were counted for each scenario, with this then providing the quantitative data for the results, on the quantities of items and hence materials at any one time and place.

The alternative modelling methods were considered but were not selected for the following reasons. Research on CLSC (Guide and Wassenhove, 2009, Savaskan et al, 2004) has marked similarities to the circular economy topic. The research often focusses on the details of organisation and structure of a CLSC, which is not the focus of this present study on understanding the effects of re-directing a flow of material. MFA has been applied to manufacturing systems (Gould and Colwill, 2015), but is better suited to relatively large, static systems, that do not require modification to represent new system arrangements.

System models that incorporate feedback loops (analogous to circular processes), can be simulated using system dynamic (SD) concepts and models (Forrester, 1961; Richardson, 1996). However, the SD approach is difficult to apply where entities are being combined to form products, which then after use might be 
separated. Similarly, "agent" based simulations are suited to modelling, for example, the movement of crowds of people, rather than tracking how and when an individual unit of material might progress along a supply chain.

DES was selected as the modelling technique for providing the quantified material flows needed as part of the analysis, due to the novelty of its use in this situation of circular flows, and due to limitations of alternative methods. The study aimed to get an overview of input information, to acquire the necessary knowledge of amounts of material that could come back in different hypothetical scenarios that consider a digital enabled re-distributed manufacturing model to assess the potential for circularity. Determining the environmental impacts was out of the scope of this study, but could be done in a further study through a life-cycle analysis (LCA) of conventional versus circular supply chains that could determine the negative or positive effects from environmental or energy perspectives.

\section{Analysis, Identification and Simulation}

\section{Case study analysis results}

Thematic analysis of each case study (Appendix A) resulted in the identification of 16 characteristics that were common to all where digital intelligence and RDM act as enablers of circularity. Appendix A identifies current system characteristics and potential barriers, to depict future opportunities for each case study. These opportunities were compared between the three case studies in a cross-case analysis to draw common conditions that could enable a circular economy (see: Table 1). 
Table 1 Cross-case analysis presenting the common conditions identified for each Lens and the relationship to Circular Economy and RDM themes

\begin{tabular}{|c|c|c|}
\hline Lens & Theme & Condition to enable a circular economy \\
\hline \multirow{3}{*}{$\begin{array}{l}\text { Supporting } \\
\text { Systems }\end{array}$} & Localization & $\begin{array}{l}\text { The three case studies are categorized as small and medium } \\
\text { enterprises with a relative small-scale operation. Also, the } \\
\text { three of them highlight decentralisation as the success of } \\
\text { their business model. The use of digital intelligence could } \\
\text { help them to maintain the small scale, decentralised } \\
\text { operations if they try to expand into a micro-factory } \\
\text { franchise model. In addition, in the case of Splosh and } \\
\text { Graze, digital intelligence could help them to develop their } \\
\text { own optimized delivery system for multi-regional locations. }\end{array}$ \\
\hline & $\begin{array}{l}\text { Distributed } \\
\text { Knowledge }\end{array}$ & $\begin{array}{l}\text { The three case studies showed opportunities for system } \\
\text { integration through the use of digital intelligence. In the } \\
\text { cases of Splosh and Graze, a single system could be used to } \\
\text { capture online orders from different products. In addition, } \\
\text { open sourced innovation could be enabled in the three cases. } \\
\text { Circularity could be enabled further through promoting user } \\
\text { attachment to the goods produced and sold by Unto This } \\
\text { Last. }\end{array}$ \\
\hline & $\begin{array}{l}\text { Distributed } \\
\text { Structure }\end{array}$ & $\begin{array}{l}\text { The three case studies removed the traditional retailer by } \\
\text { selling online and through owning their supply chain. Unto } \\
\text { This Last takes a transparent approach in which goods are } \\
\text { sold in the workshop space. In addition, further supply chain } \\
\text { integration should happen. In the case of Graze and Unto } \\
\text { This Last, both could encourage more local regional sourcing } \\
\text { by matching customer preferences to locally source } \\
\text { ingredients for snacks and materials for furniture. Also, they } \\
\text { could work with suppliers according to demand. }\end{array}$ \\
\hline Design & Customization & $\begin{array}{l}\text { The three case studies are committed to delivering high } \\
\text { quality products that are made to order. Their ability to be } \\
\text { customer focused and apply user-driven innovation to } \\
\text { improve the value proposition delivered, is due to the } \\
\text { application of digital intelligence. The use of manufacture } \\
\text { technologies enables them to produce with extreme quality } \\
\text { specifications, exactly what is ordered without } \\
\text { overproduction. With data analytics, they can process orders } \\
\text { effectively and tailor the product towards customer's } \\
\text { requirements. In addition, in the cases of Splosh and Graze, } \\
\text { they could redesign the packaging for further reuse, } \\
\text { potentially enabled by track and trace systems. }\end{array}$ \\
\hline \multirow{4}{*}{ Business Model } & $\begin{array}{l}\text { Distributed } \\
\text { Ownership } \\
\text { and/or Continued } \\
\text { Ownership }\end{array}$ & $\begin{array}{l}\text { Splosh and Graze, both offer a product and a service } \\
\text { delivery which could only be possible due to the use of } \\
\text { digital platforms such as the Internet. Unto this Last, could } \\
\text { explore the delivery of services as part of their offering. }\end{array}$ \\
\hline & $\begin{array}{l}\text { Value } \\
\text { Optimization }\end{array}$ & $\begin{array}{l}\text { Graze and Unto This Last had invested in their own software } \\
\text { development to optimize operations. Optimisation includes } \\
\text { recording customer's order history and preferences, } \\
\text { monitoring stock levels and material/ingredients used, and } \\
\text { tracking the location of workers on the factory floor. Splosh } \\
\text { is missing an opportunity by not having this system in place. }\end{array}$ \\
\hline & $\begin{array}{l}\text { Resource } \\
\text { Efficiency }\end{array}$ & $\begin{array}{l}\text { The three case studies claim to have environmental and } \\
\text { social responsibility in mind. Circularity opportunities can } \\
\text { be further explored within each of their business models, } \\
\text { particularly surrounding opportunities for End-of-Life for } \\
\text { each of their products. }\end{array}$ \\
\hline & $\begin{array}{l}\text { Economic } \\
\text { Viability }\end{array}$ & $\begin{array}{l}\text { The three case studies demonstrated opportunities to scale up } \\
\text { through micro-franchises. Use of digital intelligence could } \\
\text { help to monitor, control and optimize operations as well as } \\
\text { maintaining quality. }\end{array}$ \\
\hline
\end{tabular}




\section{Simulation models for each case study}

The cross-synthesis analysis revealed circularity opportunities for the three case studies within each lens that were further explored with the DES Model. These opportunities helped to develop possible scenarios to simulate. As Splosh already encourages users to re-use their plastic bottles, different End-of-Life options for the bottles were assumed and simulated regarding their life expectancy after being re-used several times. The scenarios were based on information sourced from the Splosh Website of life expectancy of their bottles. For Graze, a take-back-scheme for packaging was simulated, based on the fact that presently all their packaging goes to different waste streams without knowing if it gets composted or recycled. A take-back scheme could encourage re-use of their packaging but can also assure that it is composted or recycled

correctly. The scenarios are based on the number of boxes that Graze delivers in a year. For Unto-this-Last a re-manufacturing system for one of their tables was simulated, based on the assumption that furniture lifetime expectancy is about 10 years (DEFRA, 2011). The simulation models (DOI:10.17862/cranfield.rd.c.3392994) are explained below.

\section{Splosh}

The Splosh business model enables the customer to keep and re-use the detergent bottle. When more detergent is needed, a sachet with concentrated detergent is supplied, placed in the re-used bottle and diluted with water. This contrasts with a conventional business model supplying standard detergent solution in single use bottles.

A simulation model was developed for bottles of detergent, representing material movements from the manufacturer to the customer, along with the end-of-life disposal options. The model includes the supplied sachets of detergent; storage trays (made from polymer); cardboard packaging and film wrapping (see Appendix B). The 
main aspects investigated are the effect of the Splosh business model on the number of bottles required to provide the customer with detergent, plus how the Splosh business model would affect an overall manufacturing system. The simulation model was run to represent either a conventional detergent supplier using recycled material for bottles, or the Splosh business model with bottles kept for re-use, and detergent sachets supplied.

The model was run to determine how many bottles are required in a 10 year period, assuming detergent is needed every 7 weeks. Three different scenarios were investigated:

- Standard (conventional), with detergent supplied in a bottle,

- Splosh, detergent sachets, with a bottle replaced after approx. one year of use,

- Splosh, detergent sachets, with a bottle replaced after approx. three years of use.

\section{Graze}

Results of the Graze case study analysis revealed that a take-back scheme for packaging could be added to the existing business model. Graze already uses $100 \%$ recycled cardboard, and other recycled packaging. The simulation model revealed that direct take-back of packaging would give Graze the opportunity to inspect packaging and reuse it if possible. This could potentially reduce material costs, balanced against the cost of arranging returns. If packaging cannot be reused Graze can provide a "stewardship" role, by maximising the amount of material that is recycled.

Each Graze box was assumed to consist of one cardboard box, four polymer (PET) trays, four film lids, three bamboo skewers and food content. Graze delivers 300,000 of these boxes per year (Telegraph, 2016). The recycled material is already part of a circular material flow. New feedback loops are proposed to enable packaging reuse 
by Graze, with recycling where reuse is not possible. A diagram of the DES model is shown in Appendix B. The key parts are:

- Assembling items to deliver - food, skewer, polymer tray, film lid, cardboard box,

- Cardboard box supply and existing recycling option for end-of-life (EOL),

- PET polymer supply and existing recycling option for (EOL),

- Food consumption and disassembly of packaging with EOL options percentage choices for recycle or disposal for some materials,

- The new option of materials take-back by Graze, rather than use of recycled material from their suppliers.

The simulation model of the supply chain includes material suppliers and customers and focuses on the flow of packaging materials within the system. The model is used to examine the effect of increasing the amount of material being taken back directly by Graze. This will have an effect on the amounts available for recycling. Various scenarios investigated the effect of changing the ratios of materials collected for a take-back system, as shown in Table 2. The scenarios altered just one input at a time, with others held constant, performing in effect a sensitivity analysis on the significance of recovering or re-using items. The rates were varied across the full range of 0 to $100 \%$ to remove any subjectivity on pre-selecting scenarios. For each of the scenarios, the simulation allows the effect on reuse rate, recycling rate and landfill quantities to be determined. 
Table 2: Variables studied for the Graze DES model, Scenarios A - E, and Runs $1-24$.

\begin{tabular}{|c|c|c|c|c|c|}
\hline Operation & & Take-back & \multicolumn{3}{|c|}{ Graze Inspection } \\
\hline Scenario and description & Runs & $\begin{array}{l}\text { Packaging } \\
\text { recovered } \\
(\%)\end{array}$ & $\begin{array}{l}\text { Cardboard } \\
\text { reused (\%) }\end{array}$ & $\begin{array}{l}\text { PET reused } \\
(\%)\end{array}$ & $\begin{array}{l}\text { Skewers } \\
\text { reused (\%) }\end{array}$ \\
\hline $\begin{array}{l}\text { A. No take-back scheme (base } \\
\text { case) }\end{array}$ & 1 & 0 & 50 & 30 & 20 \\
\hline $\begin{array}{l}\text { B. Increasing success of the } \\
\text { take-back scheme for } \\
\text { packaging }\end{array}$ & $2-6$ & $\begin{array}{c}20,40,60 \\
80,100 \\
\end{array}$ & 50 & 30 & 20 \\
\hline $\begin{array}{l}\text { C. Increasingly durable } \\
\text { cardboard box design } \\
\text { leading to greater reuse } \\
\text { rate }\end{array}$ & $7-12$ & 60 & $\begin{array}{c}0,20,40 \\
60,80,100\end{array}$ & 30 & 20 \\
\hline $\begin{array}{l}\text { D. Increasingly durable } \\
\text { plastic tray design leading } \\
\text { to greater reuse rate }\end{array}$ & $13-18$ & 60 & 50 & $\begin{array}{c}0,20,40 \\
60,80,100\end{array}$ & 20 \\
\hline $\begin{array}{l}\text { E. Increasingly durable, } \\
\text { reusable skewers }\end{array}$ & $19-24$ & 60 & 50 & 30 & $\begin{array}{l}0,20,40 \\
60,80,100\end{array}$ \\
\hline
\end{tabular}

\section{Unto This Last (UTL)}

The DES model of UTL's manufacture and supply was created, based on a trestle table produced by UTL (Appendix B). The rate at which tables can be delivered to customers is set initially by the supply of plywood sheets that are used to manufacture the table tops, legs and crosspieces. This supply is set at two per month and is the rate at which UTL can manufacture new tables. The model simulates how many tables are supplied to customers, and how many are in use through time. The simulation model examined:

- The effects of customers choosing the length of time tables were used for - 10,5 and 2 years,

- Options once the customer decides to not use the table, including: table disposal; tables sold to a second customer; tables returned to UTL for re-manufacture.

These options are summarised in Table 3. The Base-case was a table use for 10 years, followed by disposal. The 2 nd scenario has $50 \%$ of customers selling tables on to 
a second user. Scenario 3 checks the effect of tables being sent for remanufacturing or sold to a second user. These re-manufactured tables can either be used to replace the manufacture of new tables, representing in effect a fixed demand for tables (Option a); or used to supplement the number of tables in use, with additional first-use customers being found, in effect allowing an increase in demand (Option b). Scenarios 4 and 5 examine changing table use time from 10 years, to 5 and 2 years (According to Defra 2011, lifetime expectancy of a table is 10 years). Shorter time periods were selected to explore current societal trends with consumers often electing to replace items on a more frequent basis.

Table 3: Summary of parameters varied in the Unto-This-Last trestle table simulation model

\begin{tabular}{|c|c|c|c|c|}
\hline Scenario No, and description & $\begin{array}{l}\text { Years tables } \\
\text { in use }\end{array}$ & $\begin{array}{l}\text { Tables } \\
\text { disposed (\%) }\end{array}$ & $\begin{array}{l}\text { Tables sold to } 2^{\text {nd }} \\
\text { customer }(\%)\end{array}$ & $\begin{array}{l}\text { Tables re-man } \\
\text { by UTL }(\%)\end{array}$ \\
\hline 1. Base-case & 10 & 100 & 0 & 0 \\
\hline 2. $2^{\text {nd }}$ customer, re-use & 10 & 50 & 50 & 0 \\
\hline $\begin{array}{l}\text { 3a. } \text { Remanufacture } \& 2^{\text {nd }} \\
\text { customer (Remanufacture } \\
\text { tables displaces manufacture) }\end{array}$ & 10 & 50 & 25 & 25 \\
\hline $\begin{array}{l}\text { 3b. Remanufacture } \& \\
2^{\text {nd }} \text { customer } \\
\text { (Remanufactured tables } \\
\text { added to manufacture) }\end{array}$ & 10 & 50 & 25 & 25 \\
\hline $\begin{array}{l}\text { 4a. } \text { Remanufacture } \& 2^{\text {nd }} \\
\text { customer (Remanufactured } \\
\text { tables displaces manufacture) }\end{array}$ & 5 & 50 & 25 & 25 \\
\hline $\begin{array}{l}\text { 4b. } \text { Remanufacture } \& 2^{\text {nd }} \\
\text { customer (Remanufactured } \\
\text { tables added to manufacture) }\end{array}$ & 5 & 50 & 25 & 25 \\
\hline $\begin{array}{l}\text { 5a. Remanufacture \& } 2^{\text {nd }} \\
\text { customer (Remanufactured } \\
\text { tables displaces manufacture) }\end{array}$ & 2 & 50 & 25 & 25 \\
\hline $\begin{array}{l}\text { 5b. Remanufacture } \& 2^{\text {nd }} \\
\text { customer (Remanufactured } \\
\text { tables added to manufacture) }\end{array}$ & 2 & 50 & 25 & 25 \\
\hline
\end{tabular}

\section{Simulation Results}

\section{Splosh Results}

The results from the simulation showing the number of detergent bottles used, re-used and recycled over the 10-year period is presented in Figure 1. The total number of bottle 
uses is given by the number of bottles supplied plus the number of bottle re-uses. The number of bottles supplied is equal to the number of bottles recycled plus one, since one bottle is in use by the customer.

The results reveal a very significant effect of re-using bottles by the customer, with numbers of bottles supplied reducing greatly - from 75 down to 10 or 4 over the 10 year period. The numbers of bottles recycled over 10 years is similarly much reduced from 74 to 9 and 3. A key consequence would be that much smaller amounts of material would need to be processed (i.e. manufactured and/or recycled) or transported.

\section{Insert Figure 1 here}

\section{Graze Results}

The results from the simulations for Graze are presented in Figure 2, which shows the outcomes of post-consumer materials processing options for each scenario. Boxes and trays can be reused; recycled or landfilled, skewers can be reused or landfilled. The food and film lids are not re-usable or recyclable and are either consumed or sent to landfill.

In the base case, $37 \%$ of units can be recycled with the remainder being landfilled. In the take-back simulations, increasing volumes of EoL packaging are collected by Graze. The result of increasing take-back (Scenario B) is reduction in flows to landfill from $63 \%$ to $27 \%$. The overall flow of recycled material is almost constant throughout, with a slight increase as Graze takes stewardship of EoL materials, ensuring recycling where reuse isn't impossible.

Increasing packaging durability is modelled in Scenarios C and D. The overall volume of circular material (reused or recycled) is constant in both scenarios. Landfilled material is steady at $42 \%$. Variation within the circular material flows arises from the changing ratio of reused to recycled material. More durable packaging allows higher 
reuse rates, and a proportionate decrease in recycling, as material from the recycling stream is diverted for reuse. The scenario of increased skewer re-use has reductions in the percentage of material sent to landfill, but with no change in recycling amounts, as skewers are not recyclable.

\section{Insert Figure 2 here}

\section{Unto-This-Last Results}

Results from the UTL simulation scenarios are shown in Figure 3. The base-case model with no re-use or remanufacturing shows that with a 10 -year use period the number of tables in use stabilises at around 250, and that after 20 years around 500 tables have been manufactured and supplied. When $50 \%$ of tables are re-used by a $2^{\text {nd }}$ customer, the total number of tables in use increases from years 10 to 20 to reach around 370 , the additional table uses are due to the $2^{\text {nd }}$ customers, with the overall number manufactured similar to the 500 in the base-case scenario.

The effect of introducing re-manufacturing is apparent on the overall number of tables manufactured, supplied and in use. A constant demand limits the numbers that are required to be manufactured and over 20 years the number reduces from 500 to around 430, with around 480 tables supplied overall. Using remanufactured tables as additional supply allows the overall number of tables supplied to increase to around 550, with overall numbers in use peaking at 350 .

The effect of introducing shortened usage times for tables has a very marked effect on the overall numbers of tables in use. In the 5 and 2-year models, table use peaks after a few years and then declines. In fact, in the 2-year model the number of tables in use appears to become negative after around 12 years, which is not possible, but is in artefact of the model and how the "in-use" numbers are calculated when remanufacturing is used to reduce manufactured tables. What it does indicate is that if 
customers want to replace their tables more rapidly than the manufacturing supply rate, then a shortage of tables will arise. The model results show that if re-manufactured tables can be added to those already manufactured, then at 5 and 2-year replacement intervals for tables, the numbers in use can stabilise at around 180 or 100 . These values are significantly lower than in the 10 -year use scenarios.

\section{Insert Figure 3 here}

\section{Discussion of simulation results and observations}

\section{Splosh}

For the Splosh organisation there is very little direct effect from introducing circularity in the bottle supply. Most of the effects are seen at, or after, the customer use stage, with significant impacts in other parts of the supply chain. These effects will be on the businesses involved in recycling materials and manufacturing of polymer bottles, with large reductions in mass of material and number of bottles manufactured.

For the customer the main benefits arise from only having to purchase detergent and not the bottle. This should reduce costs, and will also eliminate the need to transport the heavier, filled bottle of detergent. The impact on other businesses in the supply chain will be significant, as the amounts of material recycled and re-processed into bottles is greatly reduced, potentially causing significant disruption to these businesses.

\section{Graze}

From a materials perspective, the results are intuitive in that greater take-back reduces flows to landfill, and greater reuse of a material component results in proportionally less recycling. This information can be used to understand the economic options, business cases or energy use aspects of the supply chain, and thereby anticipate the effects of any proposed change in waste management strategy. 
The value of the take-back scheme from a circularity perspective is to divert material from landfill. This allows materials to be reused or recycled with material continuing to flow through the supply chain, and thereby reducing the amount of virgin material required to replace that which is lost to landfill, especially in RDM models (Rauch et al., 2016). However, the financial viability of material take-back depends on costs and savings. Costs would include return material collection, inspection and cleaning, and disposal of non-reusable material (Ferreira da Cruz et al., 2012). Savings are primarily from a reduction in material purchased. The proportions of re-used to recycled material are key to this calculation, with the simulation providing values for the quantities of material. A key practical consideration is whether there would be sufficient numbers of returned items and on predictable timescales (Wells and Sietz, 2005). If there is too much "leakage", then the take-back scheme could falter through lack of available items, and the simulation allows for this potential problem to be investigated.

To introduce a successful take-back scheme, the packaging and its distribution operations would require re-design to maximize the potential for reuse. More durable packaging leads to potentially more reuse, and thus greater benefit. However, the scheme needs to attract a return rate for packaging sufficient to offset the cost of packaging re-design and establishing the scheme (Guide \& Van Wassenhove 2009). Greater durability is particularly important for the non-recyclable items because reuse of this packaging directly diverts material from landfill where no recycling option exists.

\section{Unto-This-Last}

The simulation of the UTL scenarios gave insights into numbers of tables manufactured and in-use. In terms of maximising the number of tables manufactured and supplied, the 2-year replacement option gave the largest value of 640 tables, with 
the number of tables in use at any one time between being 100 and 180 . This compares with a 10-year replacement schedule which has a lower number of 480 manufactured and supplied, but which sees a higher number of 300 to 350 tables in use.

This observation high-lights the competing effects and outcomes, and whether the criteria to maximise is tables available for use or the number supplied. This is an interesting dilemma in the resource efficiency and sustainability discussion (Gutowski et al., 2011) and is highly relevant to the re-distributed manufacturing topic, because if furniture companies are operating as UTL, with products supplied to fill demand, then the company benefits financially by maximising the number supplied, rather than acting in an apparently "resource efficient" manner focussing on maximising the number inuse.

\section{Comments on all simulation results}

For all the scenarios modelled for the three organisations, assumptions have necessarily been made on numbers of items to consider and the timeframes of the activities represented in the DES models. These assumptions are felt to be reasonable, but it must be acknowledged that the quantified results should be considered as indications of what will occur, based on these initial assumptions. The conclusions are valid for the results reported, but it must be noted that different model assumptions and input values would change the results. This is the value of models for exploring options, but conclusions must be recognised as being framed within the original assumptions, which are potentially open to further discussion as part of the wider debate in the subject.

\section{Discussion and Conclusion}

The simulation results combined with the opportunities identified in the cross-case analysis, support the proposition that digital intelligence and re-distributed 
manufacturing could enhance current infrastructure in developing circular models. For instance, two of the three simulations are based on reuse (Splosh) and implementing a take-back scheme (Graze). Implementing asset tracking through the use of digital intelligence could enable the proposed improvements to their business models. Intelligent assets are already unlocking new forms of value creation, as they enable significant changes in business operations, from product design to the supply chain. Further opportunities for the food and drink sector exist to use trace and return technologies (e.g. bar codes, sensors, wireless communication and mobile devices), to select appropriate recycling methods (Saar and Thomas 2002) or account for 'short use' items (Ellen MacArthur Foundation 2016b) to divert these from landfill and reduce disposal and material costs, balanced against the cost of arranging returns. Other companies in the same sector (e.g. Abel \& $\mathrm{Cole}^{3}$ ) already have packaging take-back schemes, to allow re-use.

Circular distributed models of consumption, supported by digital intelligence could also enable premium customized services (Rüßmann et al, 2015). In the example of packaging take-back for Graze, personalized incentives and promotions could be given to encourage customers to return their packaging. However, these personalized and premium services will need to prove cost effective for both customers and the business. In the case of Unto-This-Last digital intelligence could be used to understand wear and tear of each table and provide a more personalised approach to remanufacturing and replacement of parts.

This exploratory study demonstrates that the re-distribution of systems of production and consumption could benefit the transition towards a circular economy.

\footnotetext{
${ }^{3}$ https://www.abelandcole.co.uk/
} 
Findings also uncover some of the cost-benefit dilemmas in doing so. The Splosh case study demonstrated that if a similar business model scales up there would be significant effects on the plastics industry as re-use displaces supply of material, with environmental effects requiring further quantification. With Graze, a take back scheme of packaging brings substantial economic and sustainability benefits and potentially opens a new area of operation in which 'short use' items are considered as assets. In addition, further opportunities exist by the application of digital intelligence, where circularity could be enhanced by implementing asset tracking, which could work better in re-distributed models as these allow local operations. Finally, with Unto-This-Last, a complete re-distributed model of production and consumption could be achieved by implementing a re-manufacturing system for their products. There is balancing to be made between the availability of products in use, and the number of products supplied, as this effects the financial income to the company. In addition, further study would be needed to determine whether the overall environmental effect was positive or negative. A limitation of this study was the use of secondary data and some of the assumptions made. As such, to fully understand the economic and environmental effects of the circular opportunities examined in this paper, additional research is required to calculate the environmental impacts, whether there may be re-bound effects, as well as appraising the cost-benefits.

\section{Acknowledgements:}

The EPSRC and ESRC Grant (EP/M017567/1) have funded this research as part of the Networks on Re-distributed Manufacturing. We thank our industry partners, The Clearing, Cisco and Agency of Design for their time and valuable advice in the development of this feasibility study. All complementary data for this study could be accessed via https://doi.org/10.17862/cranfield.rd.c.3392994.v1 


\section{References:}

Atasu, A., Guide, V.D.R. and Wassenhove, L.N. 2008. Product reuse economics in closed-loop supply chain research. Production and Operations Management, 17(5): 483-496.

Ayres, R.U. and Simonis, U.E. 1995. Industrial metabolism: Restructuring for sustainable development. In Fuel and Energy Abstracts. 4(36): 275.

Bakker, C.A., Wang, F., Huisman, J. and den Hollander, M. 2014. Products that go round: exploring product life extension through design. Journal of Cleaner Production, 69: 10-16.

Benyus, J. 2002. Biomimicry: invention inspired by nature. New York, USA: Harper Collins/

Bocken, N.M.P. Samuel W. Short, S.W. Rana, P. and Evans, S. 2014. A literature and practice review to develop sustainable business model archetypes. Journal of Cleaner Production, 65: 42-56.

Bocken, N.M.P., de Pauw, I., Bakker, C. and van der Grinten, B. 2016. Product design and business model strategies for a circular economy. Journal of Industrial and Product Engineer, 33: 308-320.

Carrie, A. 1988. Simulation of Manufacturing Systems. Wiley.

Chartterjee, I., Kupper, J., Mariager, C., Moore, P. \& Reis, S. 2010. The decade ahead: Trends that will shape the consumer goods industry. Consumer Packaged Goods Practice. London, UK: McKinsey and Company.

Chertow, M.R. 2007. "Uncovering” industrial symbiosis. Journal of Industrial Ecology, 11(1): 11-30.

Delloite 2015. The Deloitte Consumer Review. Made-to-order: The rise of mass personalisation. Available from: https://www2.deloitte.com/content/dam/Deloitte/ch/Documents/consumerbusiness/ch-en-consumer-business-made-to-order-consumer-review.pdf. Accessed: 01.02.18

DeVor, R.E., Kapoor, S.G., Cao, J., Ehmann, K.F., 2012. Transforming the landscape of manufacturing: distributed manufacturing based on desktop manufacturing (DM). Journal of Manufacturing Science Engineering. 134(4): 041004. 
Ellen MacArthur Foundation. 2012. Towards the circular economy: Economic and business rationale for an accelerated transition. Vol. 1. Cowes, Isle of Wight, UK: Ellen MacArthur Foundation.

Ellen MacArthur Foundation. 2013. Towards the circular economy: Opportunities for the consumer goods sector. Vol. 2. Cowes, Isle of Wight, UK: Ellen MacArthur Foundation.

Ellen MacArthur Foundation. 2014. Towards the circular economy: Accelerating the scale-up across global supply chains. Vol. 3. Cowes, Isle of Wight, UK: Ellen MacArthur Foundation.

Ellen MacArthur Foundation. 2016a. Intelligent Assets: Unlocking the Circular Economy Potential. Cowes, Isle of Wight, UK: Ellen MacArthur Foundation.

Ellen MacArthur Foundation. 2016b. The New Plastic Economy: Re-thinking the future of plastics. Cowes, Isle of Wight, UK: Ellen MacArthur Foundation.

Faludi, J., Cline-thomas, N., Agrawala S. (2017). 3D printing and its environmental implications. In: The Next Production Revolution. Implications for Governments and Businesses. OECD Publishing, Paris. Published online September 2017. DOI: http://dx.doi.org/10.1787/9789264271036-en

Ferrerira da Cruz, N., Simões, P., and Marques, R.C. 2012. Economic cost recovery in the recycling of packaging waste: the case of Portugal. Journal of Cleaner Production, 37: 8-18.

Ford, S. and Despeisse, M. 2016. Additive manufacturing and sustainability: an exploratory study of the advantages and challenges. Journal of Cleaner Production. Published online 10 May 2016. DOI: http://dx.doi.org/10.1016/j.jclepro.2016.04.150

Forrester, J. W., 1961. Industrial Dynamics. Cambridge, MA: MIT Press.

Fox, S. and Alptekin, B. 2018. A taxonomy of manufacturing distributions and their comparative relations to sustainability. Journal of Cleaner Production, 172: 1823-1834.

Freeman, R., McMahon, C. and Godfrey, P., 2017. An exploration of the potential for re-distributed manufacturing to contribute to a sustainable, resilient city. International Journal of Sustainable Engineering, 10(4-5): 260-271.

Frosch, R. and N. Gallopoulos. 1989. Strategies for manufacturing. Scientific American 261(3): 144- 152. 
Gould, O. and Colwill, J. 2015. A framework for material flow assessment in manufacturing systems. Journal of Industrial and Production Engineering, 32(1): 55-66.

Gregson, N., Crang, M., Fuller, S. and Holmes, H. 2015. Interrogating the circular economy: the moral economy of resource recovery in the EU. Economy and Society, 44(2): 218-243.

Guide V. D. R. and Wassenhove L. N. Van. 2009. The Evolution of Closed-Loop Supply Chain Research. Operations Research, 57(1), 10-18.

Gutowski, T.G., Sahni, S., Boustani, A. and Graves, S.C. 2011. Remanufacturing and energy savings. Environmental science \& technology, 45(10): 4540-4547.

Hawken, P., Lovins, A. B. and Lovins, L.H. 2013. Natural capitalism: The next industrial revolution. Routledge.

Helo, P., Suorsa, M., Hao, Y., and Anussornnitisarn, P. 2014. Toward a cloud-based manufacturing execution system for distributed manufacturing. Computers in Industry, 65(4): 646-656.

Hoornweg D., and Bhada-Tata Perinaz 2012. What a Waste. A Global Review of Solid Waste Management. No 15. Washington DC, USA: World Bank.

Itasse, S. 2008. In: TU Berlin legt Trendstudie zur Logistik vor (TU Berlin presents trend study on logistics) German Logistics Conference.

Kharas H. 2010. The Emerging Middle Class in Developing Countries. Working Paper No. 285. Paris, France: OECD Development Centre.

Kohtala, C. 2015. Addressing sustainability in research on distributed production: an integrated literature review. Journal of Cleaner Production,106: 654-668.

Lacy, P., and Rutqvist, J. 2015. Waste to Wealth. The Circular Economy Advantage. Palgrave McMillan.

Lewandowski, M. 2016. Designing the Business Models for Circular EconomyTowards the Conceptual Framework. Sustainability., 8(43):1-28.

Malik, Y., A. Niemeyer, and B. Ruwadi. 2011. Building the Supply Chain of the Future. McKinsey Quarterly. Available at: http://www.mckinsey.com/businessfunctions/operations/our-insights/building-the-supply-chain-of-the-future (Accessed 19 August 2016)

Manyika, J., Chui, M., Bisson, P., Woetzel, J., Dobbs. R., Bughin, J. \& Aharon D. 2015. The Internet of Things mapping the value beyond the hype. Mckinsey\&Company. 
Matt, D.T., Rauch, E., and Dallasega, P. 2015. Trends towards Distributed Manufacturing Systems and modern forms for their design. Procedia CIRP, 33: 185-190.

McDonough, W. and Braungart, M. 2002. Remaking the way, we make things: Cradle to cradle. New York, USA: North Point Press.

Moreno, M., and Charnley, F. 2016. Can Re-distributed Manufacturing and Digital Intelligence Enable a Regenerative Economy? An Integrative Literature Review. In Sustainable Design and Manufacturing 2016. Springer International Publishing. 563-575.

Nagurney, A. and Nagurney, L.S. 2010. Sustainable supply chain network design: A multi-criteria perspective. International Journal of Sustainable Engineering, 3(3): 189-197.

Nagurney, A., Liu, Z. and Woolley, T., 2007. Sustainable supply chain networks and transportation. International Journal of Sustainable Transportation, 1:29-51.

Parry, G. C., Brax, S. A., Maull, R. S., and Ng, I. C. 2016. Operationalizing IoT for reverse supply: the development of use-visibility measures. Supply Chain Management: An International Journal, 21(2): 228-244.

Page, B. and V. Wohlgemuth, 2007. Combining discrete event simulation and material flow analysis - a modelling tool for eco-efficiency in waver production, Proceedings of International Symposium on EcoTopia Science, ISETS07:10931098 .

Pidd, M., 1998. Computer Simulation in Management Science, $4^{\text {th }}$ Ed, Wiley.

Rahimifard, S. and Clegg, A.J., 2007. Aspects of sustainable design and manufacture. International Journal of Production Research, 45:4013-4019.

Rauch, E., Dallinger, M., Dallasega, P., Matt, D.T. 2015. Sustainability in manufacturing through distributed manufacturing systems (DMS). Procedia CIRP, 29: 544-549.

Rauch, E., Dallasega, P., and Matt, D.T. 2016. Sustainable production in emerging markets through Distributed Manufacturing Systems (DMS). Journal of Cleaner Production, 135: 127-138.

Richardson, G. P. 1996. Modelling for management, simulation in support of systems thinking. Aldershot: Dartmouth.

Robson C. 2002. Real world Research. Blackwell Publishing: UK. 
Rüßmann M., Lorenz, M., Gerbert P., Waldner M., Justus, J, Engel P., Harnisch, M. 2015. INDUSTRY 4.0. Boston Consulting Group. Available at: https://www.bcgperspectives.com/ content/articles/engineered_products_project_business_industry_40_future_prod uctivity_growth_manufacturing_industries/(Accessed 12 Feb. 2016).

Saar, S., \& Thomas, V. (2002). Toward trash that thinks: product tags for environmental management. Journal of Industrial Ecology, 6(2): 133-146.

Savaskan R. C, Bhattacharya S, Wassenhove L. N. Van, 2004. Closed-Loop Supply Chain Models with Product Remanufacturing, Management Science, 50(2): 239252

Schaffartzik, A, Mayer, A, Gingrich, S, Eisenmenger, N, Loy, C. Krausmann, F, 2014. The global metabolic transition: Regional patterns and trends of global material flows, 1950-2010. Global Environmental Change, 26:87-97.

Schatten, A. 2011. Sustainable development: the role of information and communication technology. In 5th International Vilnius Conference EURO Mini Conference: Knowledge-Based Technologies and OR Methodologies for Strategic Decisions of Sustainable Development. 17.

Srai, J. S. and Alinaghian, L.S 2013. Value Chain Reconfiguration in Highly Disaggregated Industrial Systems: Examining the Emergence of Health Care Diagnostics. Global Strategy Journal 3:88-108

Srai J.S., Kumar M., Graham. G., Phillips W., Tooze, J., Ford, S., Beecher, P., Raj, B., Gregory, M., Tiwari, M.K., Ravi, B., Neely, A., Shankar, R., Charnley, F. and Tiwari, A. 2016. Distributed manufacturing scope, challenges and opportunities. International Journal of Production Research. Published online 16 June 2016. DOI: http://dx.doi.org/10.1080/00207543.2016.1192302

Stahel, W.R. 1981. The product-life factor. In an Inquiry into the Nature of Sustainable Societies: The Role of the Private Sector. Grinton Orr, S. eds. HARC, Houston, TX. 72-96.

Stahel, W. R. 2010. The Performance Economy, 1st ed. Palgrave Macmillan: Hampshire, UK.

Stahel, W.R. 2013. The Business Angel of a Circular Economy - Higher Competitiveness, Higher Resource Security and Material Efficiency. In A New Dynamic: Effective Business in a Circular Economy, 1st ed; Ellen MacArthur Foundation eds. Cowes, The Isle of White, UK: Ellen MacArthur Foundation. 
Telegraph. 2016. Families snack on graze boxes. Available at:

http://www.telegraph.co.uk/finance/newsbysector/retailandconsumer/10439490/ Families-snack-on-graze-boxes.html (Accessed 19 August 2016)

Wells, P. and Seitz, M. (2005). Business models and closed-loop supply chains: a typology. Supply Chain Management: An International Journal, 10(4): 249-251.

$\mathrm{Xu}, \mathrm{X} ., 2012$. From cloud computing to cloud manufacturing. Robotics and computerintegrated manufacturing, 28(1): 75-86.

Yin, Robert K. 2013. Case study research: Design and methods. Sage publications.

Zanetti, C., Seregni, M., Bianchini, M. and Taisch, M., 2015. A production system model for mini-factories and last mile production approach. In: Research and Technologies for Society and Industry Leveraging a Better Tomorrow (RTSI). 2015 IEEE 1st International Forum on. IEEE. 451-456. 